theoretically, was not confirmed practically. The cases reported and examined by Ahmed Kamel had no heart defects.

3. The worms pass from the right side of the heart to the left side through the pulmonary capillaries. This, as already stated, is impossible if we know that the breadth of the male worm is $1 \mathrm{~mm}$. and the diameter of the pulmonary capillaries is 8 to $10 \mathrm{u}$. Moreover, Ahmed Kamel found no bilharziasis of lung and no eosinophilia in sputum.

Finally, I have to thank Dr. Wilson, Director of the Memorial Ophthalmic Laboratory, Giza, for allowing me to publish this case and to have the microphotographs. My thanks are also due to Dr. A. F. El-Tobgy and. Dr. Ahmed Kamel for their advice and to Dr. Farouk for providing the clinical material and the pathological specimen.

\title{
REFERENCES
}

1. ALY PASHI IBRAHIM.-Bilharziasis in Egypt, pathalogy and manifestations. Comptes rendus Congr. Inter. Méd. Trop. et Hyg., Cairo, Tome IV, pp. 499-547, 1928.

2. BYAM and ARCHIBALD. - The practice of medicine in the tropics. Vol. III, pp. 1712, 1724, 1725, 1728, 1754, 1767, 1769, 1770.

3. Diamantis. - Les tactismes en bilharziose. Comptes rendus Congr. Inter. Méd. Trop. et Hyg., Cairo, Tome IV, pp. 797-816, 1928.

4. DUke-Elder, Sir Stewart.-Text-book of Ophthalmology. London, Vol: II, p. 1670-1671, 1938.

5. Girges, Rameses.-Schistosomiasis. London, pp. 34-58, 157-186, 1934.

6. Gray's Anatomy - Twenty-third edition. Anastomoses between portal and systemic circulation. P. 761, 1926.

7. Hegner, Root and Augustine.-Animal parasitology. Pp. 266-281.

8. KAMEL, AHMED.-Schistosomiasis of the conjunctiva. Bull. Ophthal. Soc., Egypt, 1943 (not yet printed).

9. Manson-Bahr, Philip H.-Manson's Tropical Diseases. Pp. 512-515, 723-727. $19: 9$.

10. MAXIMOW.-Text-book of Histology. Pp. 332 and 354.

11. Schafer's Essentials of Histology. 12th edition, p. 235.

12. Sовну BEY, M. -Ann. d'Ocul. Tome CLXV, La Bilharziose palpebroconjonctivale, pp. 675-684, 1928.

13. Tsykales Et Cavour.-Considérations sur la "Théorie Périnéale" des infections Bilharziques et sur le "stage hepátique" de ce parasiteComptes rendus Congr. Inter. Méd. Trop. Hyg., Cairo, pp. 873-888, 1928.

14. Wilson, R. P.-Ann. Rpts. Mem. Ophthal.Lab. Giza, 1927, 1933, 1936, 1938.

\section{A CASE OF SECONDARY OBLIQUE FACIAL CLEFT*}

BY

A. Mellick, Major, R.A.M.C.

YTE. P.L., age 20 years was referred to the ophthalmic centre for treatment of blepharitis of the left eye. On examination there was seen to be present a narrow bridge of skin passsing down from the

* Received for publication, September 18, 1945. 
upper lid in the region of the lacrimal punctum to become con-tinuous with the semilunar fold (Figs. 1 and 2). In the centre of the bridge of skin, in the line of the upper lid margin, there was a small depression which admitted a fine horse hair in a medial direction for a distance of about $1.5 \mathrm{~mm}$.

The lower lid showed a slight degree of notching between the inferior punctum and the medial canthus, a shallow downward curve replacing the normal straight line of the lid margin. Fluid passed freely into the nose on syringing the lacrimal sac through the inferior punctum. X-ray examination after lipiodol injection disclosed no abnormality of the lacrimal sac and duct (Fig. 4). The caruncle was normal, and there was no interference with the motility of the globe. No other abnormality of the eye was found.

The right eye was normal, and the family history negative.

The question of the mode of origin of lid colobomata in general is not settled. They are not hereditary, and are often associated with malformations and cicatricial bands of skin in the neighbourhood. Clefts in the lids, and adhesions between the lids and globe do not occur in the course of normal development, and therefore

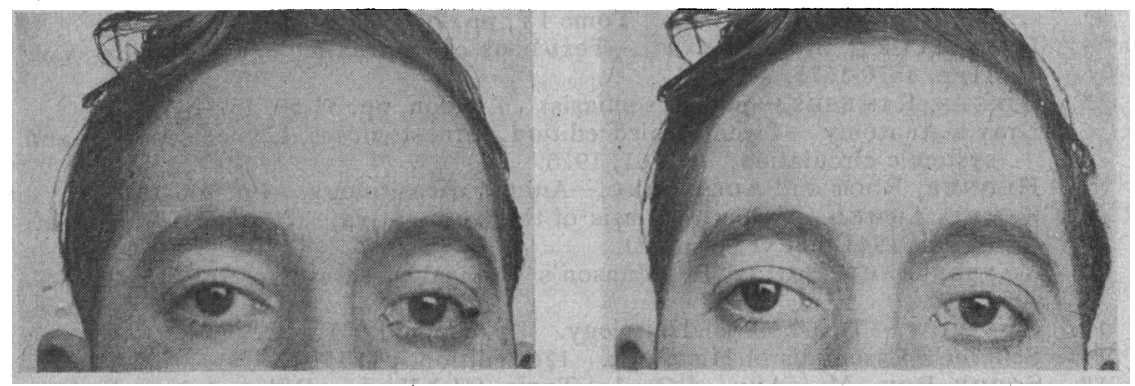

Fig. 1.

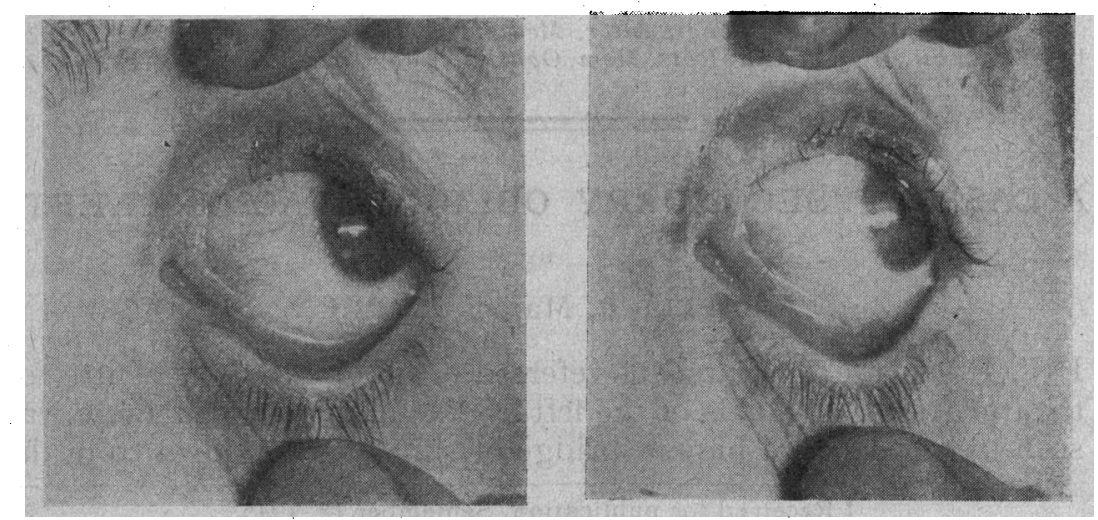

FIG. 2 . 
cannot be due to arrest of growth ${ }^{1}$. Their appearance is suggestive of some external mechanical agency, and van Duyse's theory that they are caused by the pressure of amniotic bands or adhesions explains their occurrence better than any other.

In recent years there has been much scepticism regarding the ability of amniotic bands to cause congenital defects and deformities, but this has probably been due to over-enthusiasm on the part of supporters of the theory, who have attempted to ascribe to it too large a variety of congenital anomalies. Hippel's statement ${ }^{2}$ that

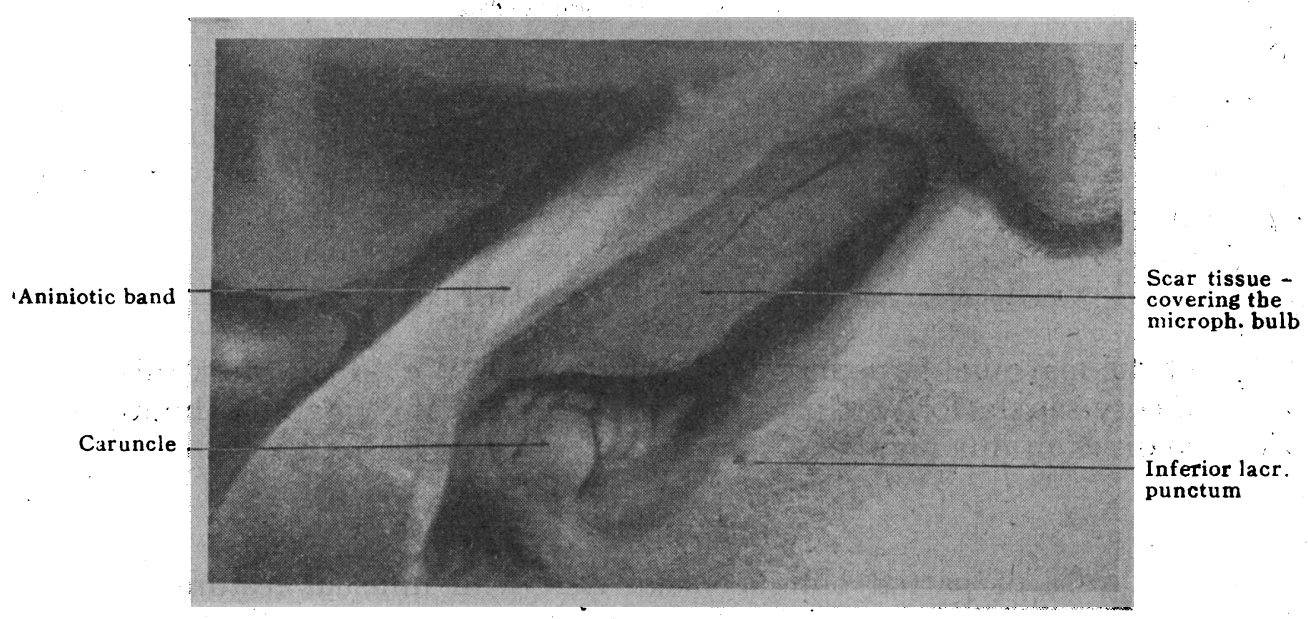

FIG. 3.

"there is no reason to repudiate the theory, or to generalise it" summarises our own views.

Fig. 3 is reproduced from the exhaustive article by Ask and van der Hoeve ${ }^{3}$, and in our opinion demonstrates conclusively that amniotic bands can effect adversely the normal course of development of the human eye. According to these authors, these bands can be effective in various positions, and according to the direction in which they occur, fifteen different types of defect can be produced, e.g., the band may pass through the sac, through either or both canaliculi, or colobomata of the lid may be produced without the canaliculi being involved. These are all included under the general heading of secondary oblique facial cleft ${ }^{4}$.

During the period of embryological development of the lids, the lid-folds become adherent, and it is during this period that differentiation of the lid-margin and its appendages occurs. Seefelder ${ }^{5}$ has suggested that failure of part of the lid to become adherent, or, alternatively, breaking down of the adhesion, would cause the defect. This theory would account for the failure in development 


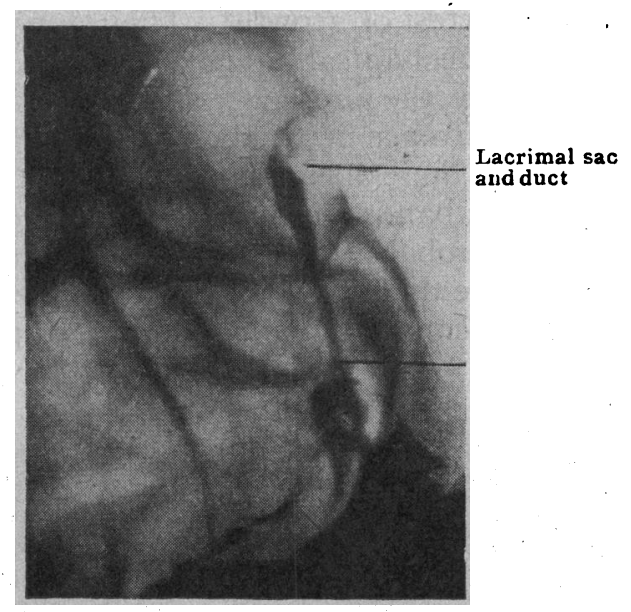

FIG. 4.

X-ray!photograph of lacrimal sac and duct after lipiodal injection.

of the marginal structures in the coloboma. We do not think this theory satisfactorily explains the great variety of congenital abnormalities in this region.

\section{Summary}

A case of partial oblique facial cleft with unusual teatures is decribed, showing non-development of the upper canaliculus, a bridge of skin passing from the upper lid to the plica semilunaris, shallow coloboma of the lower lid, with patency of the inferior canaliculus and naso-lacrimal duct. It is assumed that adhesion or pressure of amniotic bands is the cause of this anomaly.

I have to thank Professor A. Loewenstein of the Department of Ophthalmology, Glasgow University, for his valuable advice, and Mr. John Watt of the Department of Ophthalmology for the excellent photographs.

\section{REFERENCES}

1. Mann.-Developmental Abnormalities of the Eye. P. 402, 1937.

2. VON HIPPEL.- Handbuch der speziellen pathologischen Anatomie und Histologie. Wessely, Berlin. 1931.

3. AsK and VAN DER Hoeve.-Arch. f. Ophthal. Vol. CV, p. 1175, 1921.

4. M. VAN DUYSE.-Traité d'Ophtalmologie. Vol. I, p. 1035. Paris, 1939.

5. SeEFELdeR, R.-Arch.f. Ophthal., Vol. XC, p. 129, 1915. 